University of Nebraska - Lincoln

DigitalCommons@University of Nebraska - Lincoln

Sedation and Disruption of Maternal Motivation Underlie the Disruptive Effects of Antipsychotic Treatment on Rat Maternal Behavior

Changjiu Zhao

University of Nebraska-Lincoln

Ming Li

University of Nebraska-Lincoln, mli2@unl.edu

Follow this and additional works at: https://digitalcommons.unl.edu/psychfacpub

Part of the Psychiatry and Psychology Commons

Zhao, Changjiu and Li, Ming, "Sedation and Disruption of Maternal Motivation Underlie the Disruptive Effects of Antipsychotic Treatment on Rat Maternal Behavior" (2009). Faculty Publications, Department of Psychology. 414.

https://digitalcommons.unl.edu/psychfacpub/414

This Article is brought to you for free and open access by the Psychology, Department of at DigitalCommons@University of Nebraska - Lincoln. It has been accepted for inclusion in Faculty Publications, Department of Psychology by an authorized administrator of DigitalCommons@University of Nebraska - Lincoln. 


\title{
Sedation and Disruption of Maternal Motivation Underlie the Disruptive Effects of Antipsychotic Treatment on Rat Maternal Behavior
}

\section{Changjiu Zhao, Ming Li}

\author{
Department of Psychology, University of Nebraska-Lincoln, Lincoln, NE, USA
}

Correpondence to Ming Li, mli2@unl.edu

Received August 5, 2008; received in revised form November 7, 2008; accepted November 10, 2008; available online November 17, 2008; placed in the UNL Digital Commons February 4, 2010

Keywords: Antipsychotic drug, Maternal behavior, Pup-separation, Repeated antipsychotic treatment, Tolerance, Sensitization, Sedation

\begin{abstract}
The behavioral mechanisms underlying antipsychotic-induced maternal behavior deficits were examined in the present study. Different groups of postpartum rats were treated with haloperidol $(0.1 \mathrm{mg} / \mathrm{kg})$, clozapine $(10.0 \mathrm{mg} / \mathrm{kg})$, chlordiazepoxide $(5.0$ $\mathrm{mg} / \mathrm{kg}$, an anxiolytic) or vehicle ( $0.9 \%$ saline) on Days 4 and 6 postpartum and their maternal behaviors were tested under either pup-separation (e.g. pups were removed from their mothers for $4 \mathrm{~h}$ before testing) or no-pup-separation condition. Maternal behavior and drug-induced sedation were further tested for 3 days from Day 8 to 12 postpartum. Results show that pup-separation, which putatively increases maternal motivation, did significantly shorten clozapine-elongated pup approach latency, increase pup licking and nursing but fail to reverse the deficits in pup retrieval and nest building in the lactating rats treated with haloperidol and clozapine. Repeated haloperidol treatment produced a progressively enhanced disruption on pup retrieval and nest building and an attenuated sedation. In contrast, clozapine showed a progressively diminished disruption on pup retrieval and a concomitantly diminished sedative effect. Based on these findings, we suggest that antipsychotic drugs disrupt active maternal responses at least in part by suppressing maternal motivation, and drug-induced sedation also contributes to this disruptive effect, especially with clozapine.
\end{abstract}

\section{Introduction}

Clinical work on the mother-child relationship shows that the quality of maternal care from mothers with schizophrenia is generally inferior to that from healthy mothers and mothers with affective disorders (Bosanac et al., 2003; Wan et al., 2007). In comparison with healthy mothers and those with other mental disorders, schizophrenic mothers are more remote, self-absorbed, intrusive, flaccid, insensitive and unresponsive, and less demanding when taking care of their infants (McNeil et al., 1985; Näslund et al., 1985; PerssonBlennow et al., 1984, 1986; Riordan et al., 1999; Snellen et al., 1999; Wan et al., 2007). The speech of mothers with schizophrenia is less infant-focused, more negative, and with fewer songs and rhymes (Wan et al., 2008). Their infants are more avoidant (Riordan et al., 1999). One important contributing factor for the disrupted motherinfant interaction recognized by both patients and clinicians is antipsychotic medications (Awad, 1993; Awad and Hogan, 1994; Seeman, 2004). Animal work also finds that a variety of antipsychotics, from typical (e.g., haloperidol) to atypical (e.g., clozapine, risperidone, olanzapine and quetiapine), to even more recent novel antipsychotics (e.g., aripiprazole and amisulpride), possess a common disrup- tive effect on active maternal responsiveness (e.g., pup retrieval, pup licking, nest building) in postpartum rats. Acute administration of typical and atypical antipsychotics disrupts pup retrieval, pup licking, and nest building but not nursing in postpartum female rats (Giordano et al., 1990; Hansen et al., 1991a; Silva et al., 2001; Stern and Keer, 1999; Stern and Taylor, 1991). Animals under the influence of antipsychotics are slower to approach pups and retrieve fewer pups. They also spend less time licking their offspring and building the nest (Li et al., 2004a). Furthermore, novel antipsychotics (e.g., amisulpride and aripiprazole) also exhibit a certain degree of inhibition on active maternal responses in a dose-dependent fashion (Li et al., 2005a). Chronic treatment with haloperidol or olanzapine via mini-pumps or repeated daily injections significantly inhibits rat active maternal behavior as well ( $\mathrm{Li}$ et al., 2005b). It seems that the antipsychotic-induced disruption on pup retrieval, pup licking, and nest building may be an inherent feature of all currently available antipsychotics.

Although the antipsychotic-induced disruption on rat active maternal behavior is clear and robust, its underlying behavioral mechanism is not. Since maternal behavior has motivational as well as motor components, and given that antipsychotics (at least the typ- 
ical ones) are known to produce motivational and motoric impairments (Ikemoto and Panksepp, 1999; Salamone and Correa, 2002), it raises the question of whether this disruptive effect is motivational or simply motoric. In addition, because atypicals like clozapine and quetiapine also give rise to sedation due to their actions on histamine $\mathrm{H}_{1}$ receptors and/or adrenergic receptors (Fleischhacker et al., 1994), the atypical-induced disruption also could be attributed to drug-induced sedation.

The present study was designed to further investigate the behavioral mechanisms underlying antipsychotic-induced disruption on rat maternal behavior. To address the motivational versus motoric issue, we employed a pup-separation technique. Previous studies show that removing pups from dams for several hours $(>3 \mathrm{~h})$ prior to maternal testing can significantly increase a mother rat's maternal motivation (Hansen, 1994). Three to six hours of pup deprivation can completely restore pup retrieval deficits induced by massive DA depletion in the ventral striatum region in postpartum female rats (Hansen, 1994). We treated our subjects with haloperidol and clozapine and tested them under the pup-separation $(4 \mathrm{~h})$ and nopup-separation condition. If pup-separation is able to antagonize the effect of antipsychotics, it would suggest that the disruptive drug effect is mainly exerted on animals' motivation rather than on their motoric functions.

To examine to what extent antipsychotic drug-induced sedation contributes to their disruption on active maternal behavior, we employed a repeated treatment schedule and compared effect of antipsychotics with that of chlordiazepoxide, an anxiolytic drug with a sedative effect (File, 1984). It is well known that with repeated drug administration, the sedative effect of antipsychotics and anxiolytics is greatly diminished (Chesler and Salamone, 1996), and tolerance can be seen with only four injections (File, 1984; Sanger, 1985). In the meantime, antipsychotic efficacy is progressively enhanced with repeated drug administration (Agid et al., 2003; Li et $a l ., 2007)$. If drug-induced sedation plays a role in disrupting active maternal behavior, we expect that the haloperidol- and clozapineinduced maternal behavior deficits would show an improvement with repeated drug treatment. If this disruptive effect mainly reflects the effect of dopamine blockade (Li et al., 2004a), the haloperidoland clozapine-induced deficits would persist and show a deterioration with repeated drug treatment.

\section{Materials and methods}

\subsection{Subjects}

Forty-six 2 or 3 month old pregnant female Sprague-Dawley rats purchased from Charles River Inc. (Portage, MI) or mated at the colony were used in this study. All rats were housed individually in $48.3 \mathrm{~cm} \times 26.7 \mathrm{~cm} \times 20.3 \mathrm{~cm}$ transparent polycarbonate cages under 12-h light/dark conditions (light on between 6:30 am and 6:30 pm). The temperature-controlled colony was maintained at approximately $23^{\circ} \mathrm{C}$. Experiments were conducted during the light cycle. The rats had free access to food and tap water in their home cages. All animal procedures were conducted in accordance to the National Institutes of Health Guide for the Care and Use of Laboratory Animals, and approved by the University of Nebraska Institutional Animal Care and Use Committee.

\subsection{Drugs and choices of dosage}

The injection solutions of haloperidol (HAL, $5.0 \mathrm{mg} / \mathrm{ml}$ ampoules, Sabex Inc., Boucherville, Quebec, Canada) and chlordiazepoxide (CDP, Sigma-Aldrich, St. Louis, MO) were obtained by mixing the drugs with sterile water. Clozapine (CLZ, a gift from NIMH drug supply program) was dissolved in $1.0 \%$ glacial acetic acid in distilled water. HAL, CLZ, and vehicle water were administered sub- cutaneously, whereas CDP was administered intraperitoneally. We chose $0.1 \mathrm{mg} / \mathrm{kg}$ HAL and $10.0 \mathrm{mg} / \mathrm{kg}$ CLZ because these doses have been shown to effectively disrupt active maternal behavior $(\mathrm{Li}$ et al., 2004a). At the chosen doses, HAL and CLZ provided opamine $\mathrm{D}_{2}$ receptor occupancies in animals comparable to those observed in patients, approximately $50 \%-70 \%$ striatal $\mathrm{D}_{2}$ occupancy (Kapur et al., 2003). Thus, this dose selection enabled us to evaluate different drugs on a common ground at the clinically relevant dose. We also included CDP as a pharmacological control. CDP, like atypical CLZ, also gives rise to sedation (File, 1984) but lacks the antipsychotic effect. We chose $5.0 \mathrm{mg} / \mathrm{kg}$ CDP because it is an effective anxiolytic dose used in other behavioral models (Joordens et al., 1998; Klint, 1991; Li et al., 2004b) and more importantly, its sedative effect shows a similar time course (File, 1984) to that of clozapine (Sanger,1985).

\subsection{Basic experimental procedure}

Starting 2 or 3 days prior to the first possible expected parturition date, the subjects were monitored every morning for signs of parturition. Once the dam was found with pups in the morning (that day was designated as Day 1 postpartum), the mother was transferred into a clean cage with wood shavings for bedding. Two shredded paper towels were also provided for nesting material. The litter was culled to 8 pups ( 4 males and 4 females with the most visible milk bands). Maternal behavior tests were conducted from Day 4 to 12 postpartum.

\subsection{Maternal behavior test}

Each test consisted of two phases. The first was a spot-check observation of maternal behavior under undisturbed condition. Using a laptop computer with an event recording program (JWatcher, http:/ / www.jwatcher.ucla.edu/), we recorded the location of mother rats and their pups and rated the quality of the nest on a 5-point scale according to the criteria of Lonstein and Fleming (2002). The second phase was an 8-min pup retrieval behavior test starting immediately after the first undisturbed test. This phase was initiated by taking the 8 pups away from the mother and destroying the nest. Ten seconds later, the pups were placed in the corner of the cage diagonal to the nest site or dam sleeping corner. When the subject picked up a pup in her mouth and carried it back to the nest site, it was referred to as a successful pup retrieval. Approach latency was defined as the time taken form other rats to approach and sniff the pups from the reunion. First and last pup retrieval latency was defined as the time elapsed from the first pup approach to the retrieval of the first and eighth pup into the nest respectively. A score of $480 \mathrm{~s}$ was assigned to non-responders who did not approach or retrieve the testing pups. The total number of pups retrieved was recorded. The occurrence of other behaviors was also recorded, including pup nursing behavior (a rat positioning herself over the pups with legs splayed to accommodate the pups, including hover, high and low crouching over postures), pup licking (a female rat placing its tongue on the anogenital area and the rest of a pups body), nest building (a rat picking up nesting material in her mouth and transporting it back to the nest site or pushing the material with her forepaws toward the nest site). After the test, any unretrieved pups were returned to the nest site. The observers were unaware of the drug condition of each subject.

\subsection{Experiment 1. Effects of pup-separation on the acute antipsychotic- induced maternal behavior deficits}

Four groups of postpartum rats (HAL- $0.1 \mathrm{mg} / \mathrm{kg}$, CLZ- $10.0 \mathrm{mg} /$ $\mathrm{kg}$, CDP- $5.0 \mathrm{mg} / \mathrm{kg}$, and vehicle water, $n=12$ per group for HAL, CLZ and vehicle; $n=10$ for CDP) were used. On Day 4 postpartum, the first maternal behavior test started $0.5 \mathrm{~h}$ before drug injections (i.e., baseline). The second and third tests were carried out at $2 \mathrm{~h}$ and $4 \mathrm{~h}$ after the drug or vehicle injection. We performed across-over 
(change-over) trial with variants of the two-treatment, two-period design. Half of the mother rats allocated at random to each group ( $n=6$ for HAL, CLZ and vehicle; $n=5$ for CDP) were tested under the pup-separation condition in which their pups were taken away from them $4 \mathrm{~h}$ before the second test on that day. Pups were placed into a bowl with nesting material on a temperature-controlled heating pad $\left(34^{\circ} \mathrm{C}\right)$. The other half of the mother rats were tested without separation from their pups (no-pup-separation condition). On Day 6 postpartum, the same procedure was applied, but the rats started on the pup-separation condition on Day 4 started on the no-pup-separation condition, and ones previously started on the no-pup-separation condition started on the pup-separation condition (a complete counter balanced design). This cross-over design allowed us to consecutively test each subject which received two experimental manipulations during the course of the experiment. Various measures of maternal behavior were recorded (see below for testing details).

2.6. Experiment 2. Effects of repeated antipsychotic treatment on maternal behavior in rats

The above four groups of postpartum rats were used in this experiment. After 2 days of rest, rats were treated with the same drug as before and tested on Days 8, 10 and 12 postpartum. On each drug test day, maternal behaviors were measured at 4 time points, with the first one at $0.5 \mathrm{~h}$ before the drug injections (i.e., baseline), and the rest at 1,2 , and $4 \mathrm{~h}$ after the drug injection. In addition to maternal behavior tests, the characteristics of sedation (e.g., eye closed, head down, curled up in a ball, flattened posture, ataxia, problems with limb placement, lack of alertness, general appearance of sleepiness) were concurrently observed. The sedative manifestations of mother rats were further assessed for 30-sec periods according to a sedation rating adapted from Chesler and Salamone (1996): 4 = awake, active: engaged in locomotion, rearing or head movement; $3=$ awake, inactive: eyes fully open, head up, no locomotion or rearing, normal posture; 2 = moderate sedation: eyes partly closed, head somewhat down; 1 = heavy sedation: eyes mostly closed, head mostly or entirely down, flattened posture, lack of normal limb placement; $0=$ asleep.

\subsection{Data analysis}

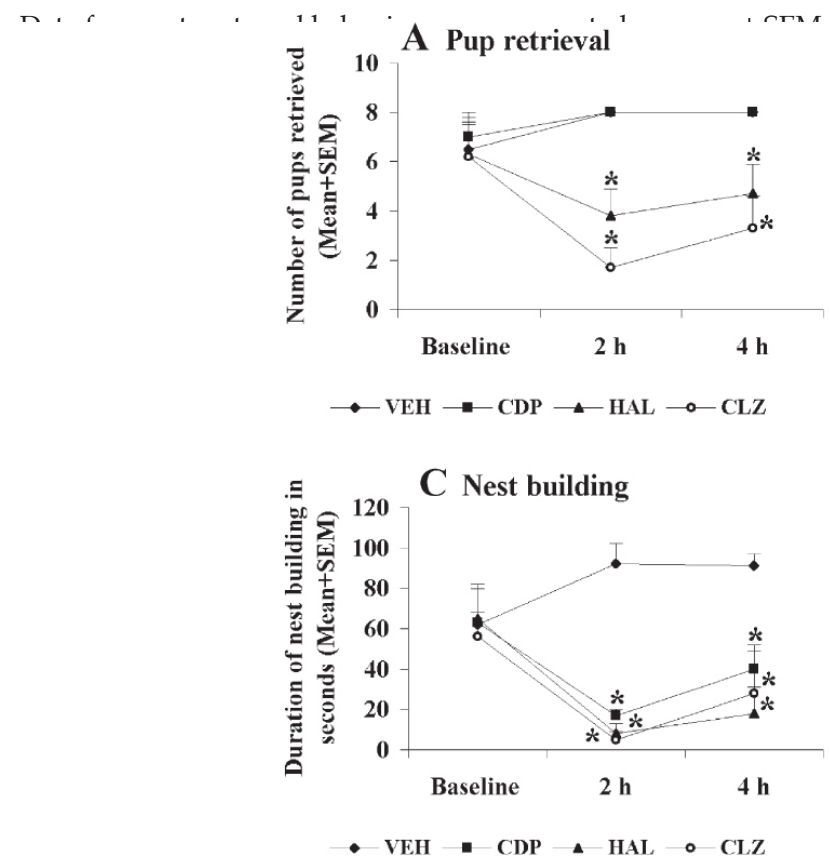

To examine the acute and chronic treatment effects, data were analyzed using a factorial repeated measures analysis of variance (ANOVA) with the between-subject fact or being the treatment condition (HAL, CLZ, CDP and VEH) and the within-subject factors being the testing time points (e.g. baseline, $1 \mathrm{~h}, 2 \mathrm{~h}$ and $4 \mathrm{~h}$ ) or days (Days 8, 10, and 12). Group differences were further investigated using simple main effect tests (one-way ANOVA) followed by LSD post hoc tests for multiple comparisons where appropriate. To examine the pup-separation effect, data from the Day 4 and Day 6 under the same testing condition (e.g. pup-separation on Day 4 and Day 6) were combined and analyzed using Paired-Samples $T$ test.

For the latency and sedation data, because they were not normally distributed (e.g. the cut-off time set at $480 \mathrm{~s}$ for the latency data, and the sedation was ranking data), data for latency and sedation were displayed as median \pm interquartile range. Nonparametric Kruskal-Wallis test was used for analyzing the difference between the drug treatment groups. Once the overall significant effects were determined, two-group comparisons between the drug and vehicle treatment were performed using Mann-Whitney $U$ test. Separation effect was examined by comparing maternal behavior tested under the pup-separation condition with that tested under the no-separation condition using Wilcoxon Two Related-Samples tests. Correlation between the disruptive effect on pup retrieval and sedation of the drugs was tested using Spearman's rank correlation analysis to evaluate the possible influence of drug-induced sedation on maternal behavior. A conventional two-tailed level of significance at the 0.05 level was required.

\section{Results}

3.1. Experiment 1. Effects of pup-separation on the acute antipsychoticinduced maternal behavior deficits

3.1.1. Acute haloperidol and clozapine treatment impaired active components of maternal behavior

To identify the acute effect of antipsychotic treatment on maternal behavior, we examined maternal behavior of the four groups tested under the regular condition (no-pup-separation) on Day 4 postpartum (see Figure 1). Consistent with our previous report ( $\mathrm{Li}$ et al.,
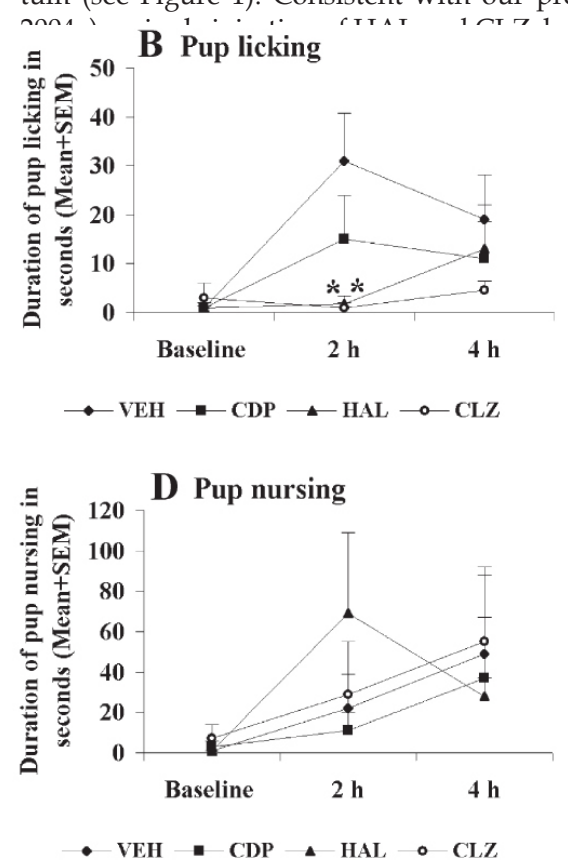

Fig. 1. Various maternal behaviors tested at different time points (baseline, $2 \mathrm{~h}$ and $4 \mathrm{~h}$ post-injection) under the no-pup-separation condition after a single injection of HAL, CLZ, CDP or vehicle on Day 4 postpartum. HAL and CLZ, but not CDP significantly disrupted pup retrieval (A) and pup licking (B), whereas all drugs consistently disrupted nest building (C), but not pup nursing (D). Data were expressed as mean + SEM. $* P<0.05$ indicates a significant difference between one drug group and the vehicle group. 
disrupted various active components of maternal behavior. Rats treated with HAL and CLZ took a much longer time to approach and retrieve their pups into the nest sites (data not shown) and retrieved less pups at $2 \mathrm{~h}$ and $4 \mathrm{~h}$ testing points (all $p \mathrm{~s}<0.05$ ). They also spent less time on pup licking and nest building (One-way ANOVA and LSD post hoc test, all $p \mathrm{~s}<0.05)$. However, nursing activity was not significantly affected by any drug treatment. CDP only impaired nest building ( $p<0.01$ for $2 \mathrm{~h}, p<0.05$ for $4 \mathrm{~h}$ ), suggesting that this behavior may be more vulnerable than others to the disruptive effect of drug treatment.

3.1.2.Pup-separation shortened pup approach latency and increased pup licking and pup nursing, but failed to reverse pup retrieval deficit

To examine the effects of pup-separation on maternal behavior under the influence of antipsychotics, we compared the maternal behavior data obtained under the pup-separation condition from Days 4 and 6 postpartum with those obtained under the no-pupseparation condition from both days. Once again, in comparison to the vehicle, HAL disrupted pup retrieval and CLZ inhibited the dams' approach and retrieval of their pups in this data set. Pup-separation significantly shortened CLZ-treated pup approach latency (Table 1) but failed to alleviate the pup retrieval deficits, as there was no significant improvement in the first and last pup retrieval latency (Table 1) and in the number of pups retrieved (Figure 2A). Repeated measures ANOVA on the number of pups retrieved revealed a significant main effect of drug treatment $\left[F_{(3,42)}=14.58, p=0.000\right.$ for $2 \mathrm{~h}$; $F_{(3,42)}=11.68, p=0.000$ for $\left.4 \mathrm{~h}\right]$, but no significant effect of separation or interaction between the drug treatment and pup-separation. Pupseparation also did not affect the nest building activity (Figure 2C). Repeated measures ANOVA revealed a main effect of drug treatment $\left[F_{(3,42)}=28.64, p=0.000\right.$ for $2 \mathrm{~h} ; F_{(3,42)}=16.79, p=0.000$ for $\left.4 \mathrm{~h}\right]$, but no significant effect of separation or interaction between the two factors.

Most prominently, pup-separation did substantially increase the amount of time spent by the mothers on licking (Figure 2B) and nursing(Figure 2D). For pup licking, repeated measures ANOVA revealed a main effect of drug treatment $\left[F_{(3,42)}=6.43, p=0.001\right]$, a significant effect of separation $\left[F_{(1,42)}=36.07, p<0.001\right]$, and a significant interaction between the two factors $\left[F_{(3,42)}=3.29, p=0.030\right]$ at the $2 \mathrm{~h}$ testing point. Two-group comparisons (or one-way ANOVA) revealed that pup-separation consistently enhanced duration of pup licking across all treatment groups at the $2 \mathrm{~h}$ point $(p<0.01$ for VEH and CDP, $p<0.05$ for HAL and CLZ). For pup nursing, repeated measures ANOVA revealed a significant effect of separation $\left[F_{(1,42)}=32.03, p\right.$ $=0.000]$, but no main effect of drug treatment or significant interaction between the two factors at the $2 \mathrm{~h}$ point. Further analysis with
Paired-Samples T test showed that separation significantly enhanactivity across all four groups at the $2 \mathrm{~h}$ post-injection testing point $(p$ $<0.01$ for VEH, CDP; $p<0.05$ for HAL, CLZ). It should be noted that although we used the combined data to examine the effects of pup-separation, the same results were obtained when the data from Days 4 and 6 postpartum were not combined and analyzed separately.

3.2. Experiment 2. Effects of repeated antipsychotic treatment on maternal behavior in rats

As can be seen in Figure 3, with repeated drug administration, HAL progressively enhanced its disruption on pup retrieval and maintained its disruption on pup approach, pup licking, and nest building. In contrast, CLZ showed a progressively attenuated disruption on pup approach and retrieval but maintained its disruption on pup licking and nest building.

\subsubsection{Latency to approach and retrieve pups}

With repeated drug administration, HAL produced persistent disruption of the pup approach latency and the first and last pup retrieval latency over 4 sessions across the three test days (data not shown), whereas CLZ exerted this disruptive effect at $1 \mathrm{~h}$ and $2 \mathrm{~h}$ (all $p<0.01$ ) only on the first testing day. CDP treatment had no significant effect on pup approach and pup retrieval latency (data not shown).

\subsubsection{Pup retrieval}

With repeated drug treatment, HAL progressively reduced the number of pups retrieved, whereas the disruptive effects of CLZ on this behavior were diminished. CDP had no significant effect in this regard. Repeated measures ANOVA revealed a significant main effect of drug treatment $\left[F_{(3,40)}=4.16, p=0.012\right.$ for baseline; $F_{(3,40)}=$ $10.17, p<0.001$ for $1 \mathrm{~h} ; F_{(3,40)}^{(3,40)}=11.28, p<0.001$ for $2 \mathrm{~h} ; F_{(3,40)}=8.64$, $p<0.001$ for $4 \mathrm{~h}$, no significant effect of test day, but a significant interaction between the two factors $\left[F_{(6.80)}=1.21, p=0.031\right.$ for baseline; $F_{(6,80)}=3.48, p=0.004$ for $1 \mathrm{~h} ; F_{(6,80)}=7.06, p<0.001$ for $2 \mathrm{~h} ; F_{(6,80)}$ $=4.00, p=0.001$ for $4 \mathrm{~h}]$. Post hoc tests showed that HAL significantly disrupted retrieval activity at $1 \mathrm{~h}, 2 \mathrm{~h}$, and $4 \mathrm{~h}$ testing points (all $\mathrm{ps}<$ $0.05)$ across the test days, even at the baseline on Day 10 postpartum $(p=0.030)$; whereas CLZ impaired pup retrieval at $1 \mathrm{~h}, 2 \mathrm{~h}$, and $4 \mathrm{~h}$ post-injection testing points (all $p s<0.05$ ) only on Day 8 postpartum. Additionally, Paired Samples $T$ tests comparing the data on Day 8 to Day 12 postpartum showed that with repeated drug administration, the disruptive effect of HAL was progressively potentiated, whereas CLZ showed a progressively attenuated disruption (all $p s<0.05$ ).

Table 1

Effects of pup-separation on pup approach latency and pup retrieval latency in postpartum female rats treated with HAL, CLZ, CDP and vehicle

\begin{tabular}{|c|c|c|c|c|c|c|c|c|c|c|c|}
\hline \multirow[t]{2}{*}{ Groups } & \multirow[t]{2}{*}{$N$} & \multirow[t]{2}{*}{ Condition } & \multicolumn{3}{|c|}{ Approach latency (s) } & \multicolumn{3}{|c|}{ First pup retrieval latency (s) } & \multicolumn{3}{|c|}{ Last pup retrieval latency (s) } \\
\hline & & & Baseline & $2 \mathrm{~h}$ & $4 \mathrm{~h}$ & Baseline & $2 \mathrm{~h}$ & $4 \mathrm{~h}$ & Baseline & $2 \mathrm{~h}$ & $4 \mathrm{~h}$ \\
\hline \multirow[t]{2}{*}{$\overline{\mathrm{VEH}}$} & 12 & No-separation & $\begin{array}{l}3.6 \\
(2.9)\end{array}$ & $\begin{array}{l}3.3 \\
(4.0)\end{array}$ & $\begin{array}{l}5.2 \\
(5.2)\end{array}$ & $\begin{array}{l}15.8 \\
(100.9)\end{array}$ & $\begin{array}{l}3.3 \\
(1.9)\end{array}$ & $\begin{array}{l}4.2 \\
(15.7)\end{array}$ & $\begin{array}{l}220.9 \\
(409.6)\end{array}$ & $\begin{array}{l}58.1 \\
(41.5)\end{array}$ & $\begin{array}{l}50.4 \\
(50.3)\end{array}$ \\
\hline & 12 & Separation & $\begin{array}{l}2.3 \\
(2.5)\end{array}$ & $\begin{array}{l}1.8 \\
(0.6)\end{array}$ & $\begin{array}{l}2.4 \\
(3.2)\end{array}$ & $\begin{array}{l}2.7 \\
(28.1)\end{array}$ & $\begin{array}{l}2.0 \\
(8.7)\end{array}$ & $\begin{array}{l}2.6 \\
(2.5)\end{array}$ & $\begin{array}{l}40.9 \\
(175.8)\end{array}$ & $\begin{array}{l}43.3 \\
(66.1)\end{array}$ & $\begin{array}{l}31.6 \\
(23.1)\end{array}$ \\
\hline \multirow[t]{2}{*}{ CDP } & 10 & No-separation & $\begin{array}{l}3.8 \\
(3.5)\end{array}$ & $\begin{array}{l}4.5 \\
(4.7)\end{array}$ & $\begin{array}{l}2.3 \\
(1.1)\end{array}$ & $\begin{array}{l}2.6 \\
(8.7)\end{array}$ & $\begin{array}{l}2.6 \\
(3.5)\end{array}$ & $\begin{array}{l}1.7 \\
(0.8)\end{array}$ & $\begin{array}{l}41.9 \\
(176.2)\end{array}$ & $\begin{array}{l}26.4 \\
(29.1)\end{array}$ & $\begin{array}{l}17.1 \\
(21.5)\end{array}$ \\
\hline & 10 & Separation & $\begin{array}{l}3.2 \\
(2.5)\end{array}$ & $\begin{array}{l}2.2 \\
(4.0)\end{array}$ & $\begin{array}{l}2.6 \\
(3.0)\end{array}$ & $\begin{array}{l}2.3 \\
(21.3)\end{array}$ & $\begin{array}{l}1.9 \\
(3.0)\end{array}$ & $\begin{array}{l}2.3 \\
(7.4)\end{array}$ & $\begin{array}{l}47.6 \\
(369.4)\end{array}$ & $\begin{array}{l}26.4 \\
(64.8)\end{array}$ & $\begin{array}{l}18.1 \\
(31.6)\end{array}$ \\
\hline \multirow[t]{2}{*}{ HAL } & 12 & No-separation & $\begin{array}{l}2.9 \\
(2.7)\end{array}$ & $\begin{array}{l}4.4 \\
(32.9)\end{array}$ & $\begin{array}{l}3.8 \\
(12.6)\end{array}$ & $\begin{array}{l}4.9 \\
(22.2)\end{array}$ & $\begin{array}{l}4.5 \\
(360.1)\end{array}$ & $\begin{array}{l}4.5 \\
(33.1)\end{array}$ & $\begin{array}{l}184.6 \\
(417.1)\end{array}$ & $\begin{array}{l}480.0^{\mathrm{a}} \\
(423.8)\end{array}$ & $\begin{array}{l}480.0^{\mathrm{a}} \\
(415.0)\end{array}$ \\
\hline & 12 & Separation & $\begin{array}{l}4.7 \\
(5.8)\end{array}$ & $\begin{array}{l}2.9 \\
(1.6)\end{array}$ & $\begin{array}{l}4.1 \\
(5.3)\end{array}$ & $\begin{array}{l}18.1 \\
(43.0)\end{array}$ & $\begin{array}{l}207.3 \\
(477.6)\end{array}$ & $\begin{array}{l}97.6 \\
(476.0)\end{array}$ & $\begin{array}{l}430.2 \\
(392.2)\end{array}$ & $\begin{array}{l}480.0 \\
(297.3)\end{array}$ & $\begin{array}{l}480.0 \\
(303.2)\end{array}$ \\
\hline \multirow[t]{2}{*}{ CLZ } & 12 & No-separation & $\begin{array}{l}3.1 \\
(1.9)\end{array}$ & $\begin{array}{l}19.9^{\mathrm{a}} \\
(16.9)\end{array}$ & $\begin{array}{l}4.4 \\
(23.3)\end{array}$ & $\begin{array}{l}31.3 \\
(370.5)\end{array}$ & $\begin{array}{l}55.4^{\mathrm{a}} \\
(473.2)\end{array}$ & $\begin{array}{l}3.9 \\
(50.7)\end{array}$ & $\begin{array}{l}329.7 \\
(367.3)\end{array}$ & $\begin{array}{l}480.0^{\mathrm{a}} \\
(280.6)\end{array}$ & $\begin{array}{l}276.2 \\
(432.9)\end{array}$ \\
\hline & 12 & Separation & $\begin{array}{l}4.1 \\
(15.2)\end{array}$ & $\begin{array}{l}3.0^{\mathrm{b}} \\
(7.7)\end{array}$ & $\begin{array}{l}4.1 \\
(16.9)\end{array}$ & $\begin{array}{l}14.1 \\
(31.9)\end{array}$ & $\begin{array}{l}480.0 \\
(471.3)\end{array}$ & $\begin{array}{l}3.5 \\
(293.2)\end{array}$ & $\begin{array}{l}92.3 \\
(430.5)\end{array}$ & $\begin{array}{l}480.0 \\
(294.6)\end{array}$ & $\begin{array}{l}286.7 \\
(427.4)\end{array}$ \\
\hline
\end{tabular}

${ }^{a} p<0.05$ indicates a significant difference between one drug group and the vehicle group under the no-separation condition.

b $p<0.05$ indicates a significant difference between the pup-separation and no-pup-separation condition. Data are expressed as median \pm interquartile range. 
A Pup retrieval $\square$ No-separation
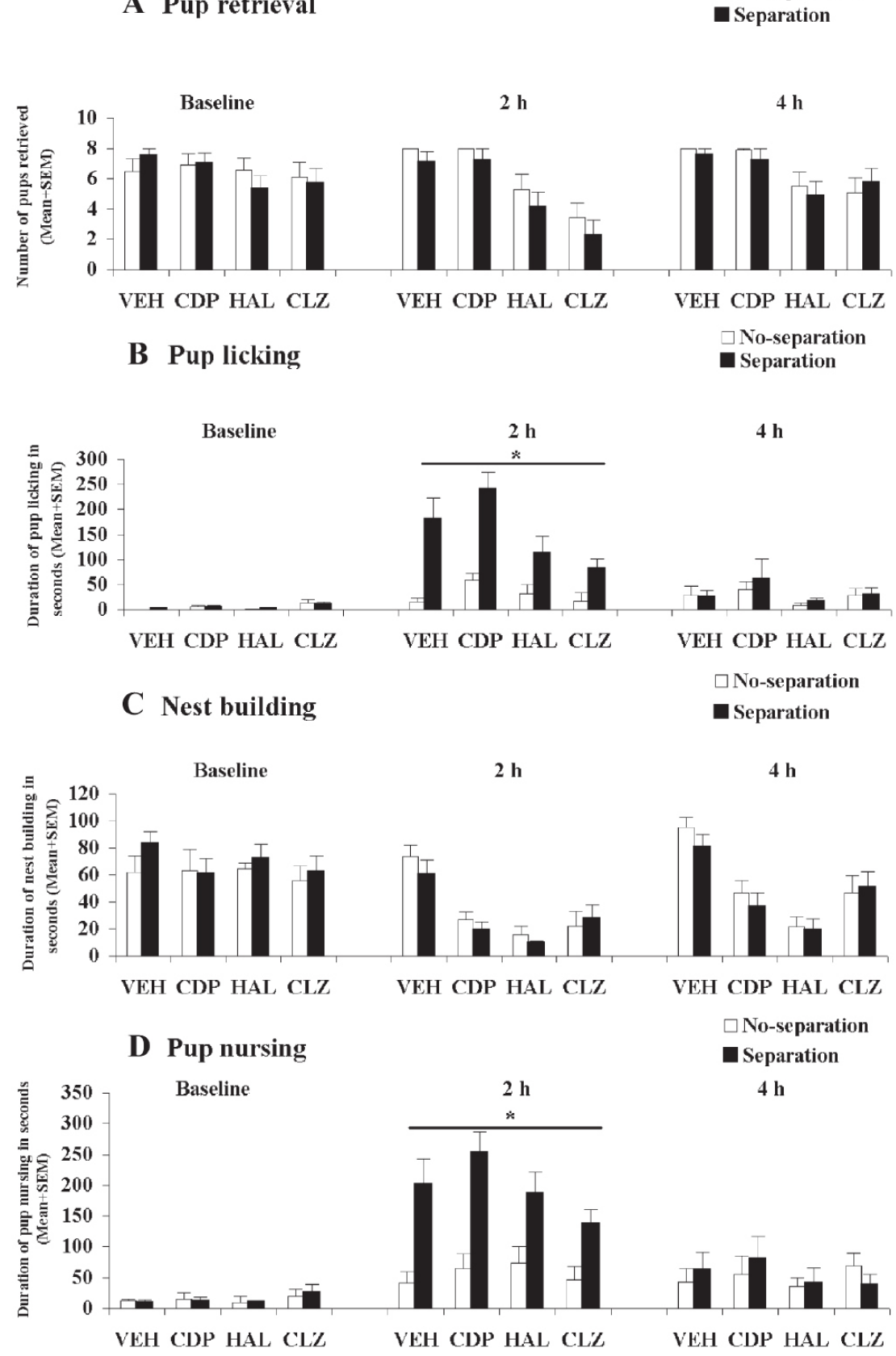

Fig. 2. Pup retrieval (A), pup licking (B), nest building (C) and pup nursing (D) tested at different time points (baseline, $2 \mathrm{~h}$ and $4 \mathrm{~h}$ post-injection) under the pup-separation or no-pupseparation condition. Data from Day 4 and Day 6 postpartum were combined. Under the pup-separation condition, pups were removed from their mother rats until $4 \mathrm{~h}$ before testing. Pup-separation significantly enhanced the duration of pup licking and nursing at $2 \mathrm{~h}$ testing point. Data were expressed as mean + SEM. $* P<0.05$ indicates a significant difference between the pup-separation and no-pup-separation condition.

\subsubsection{Pup licking}

Repeated measures ANOVA revealed a main effect of drug treatment $[F(3,40)=12.36, p<0.001$ for $1 \mathrm{~h} ; F(3,40)=17.80, p<0.001$ for 2 $\mathrm{h}]$, no significant effect of test time or significant interaction between the two factors at $1 \mathrm{~h}$ or $2 \mathrm{~h}$ testing point. Post hoc tests showed that HAL significantly impaired pup licking activity at $2 \mathrm{~h}$ post-injection (both $p s<0.05$ ), while CLZ did so at $1 \mathrm{~h}$ and $2 \mathrm{~h}$ on Day 10 and Day 12 postpartum (both ps $<0.05$ ). As opposed to HAL and CLZ, CDP produced a significant enhancing effect on pup licking at $1 \mathrm{~h}$ and 2 $\mathrm{h}$ testing points on Day 8 postpartum (both ps $<0.05$ ). No long-term potentiation or attenuation of the drug effect on pup licking activity was observed (Paired Samples $T$ test, Day 8 vs Day 12, all $p$ s > 0.05).

\subsubsection{Nest building}

Repeated measures ANOVA revealed a main effect of drug treatment (all $p \mathrm{~s}<0.001$ ), no significant effect of test day, but a significant interaction between the two factors (all $p s<0.05$ ) at $1 \mathrm{~h}, 2 \mathrm{~h}$, and 4 $\mathrm{h}$ testing points; there was a main effect of drug treatment $[F(3,40)$ $=12.27, p=0.045]$, a significant effect of test time $[F(2,80)=6.57, p$ $=0.002]$, but no significant interaction between the two factors at the baseline level. Post hoc tests showed that HAL significantly disrupted nest building activity at $1 \mathrm{~h}, 2 \mathrm{~h}, 4 \mathrm{~h}$ testing points (all $p \mathrm{~s}<$ $0.05)$ across the three test days, at the baseline on Day $10(p=0.013)$ and Day 12 postpartum ( $\mathrm{p}=0.015)$; whereas CLZ impaired pup retrieval at $1 \mathrm{~h}$ and $2 \mathrm{~h}$ across the test days (all ps $<0.05)$ and at $4 \mathrm{~h}$ 


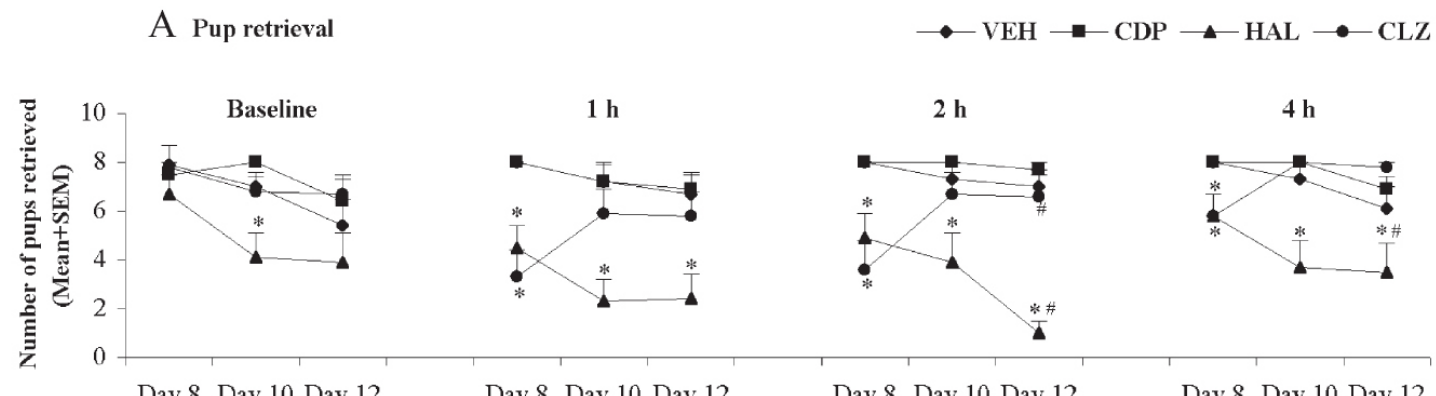

Postpartum days

B Pup licking
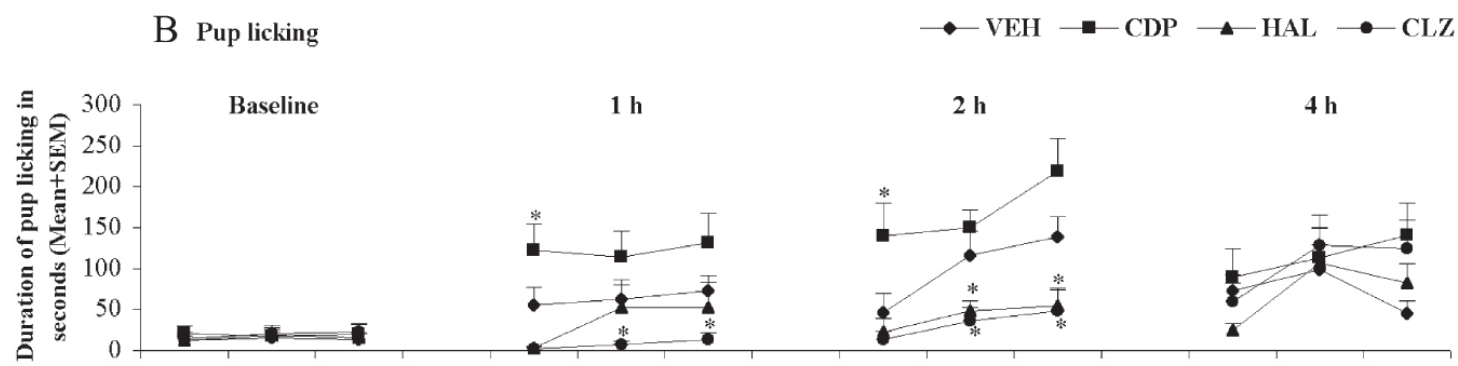

$1 \mathrm{~h}$

$2 \mathrm{~h}$

$4 \mathrm{~h}$

Day 8 Day 10 Day 12
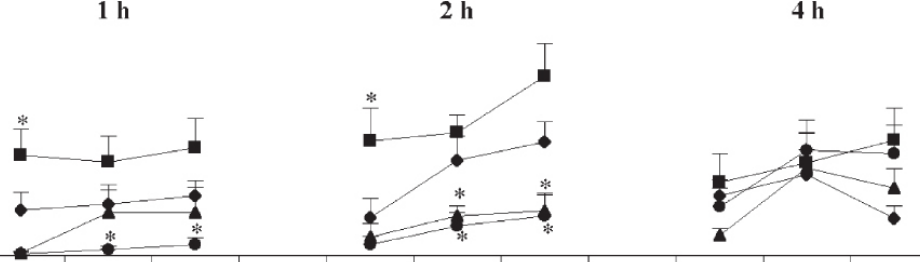

Day 8 Day 10 Day 12

Day 8 Day 10 Day 12

Day 8 Day 10 Day 12

Postpartum days

C Nest building

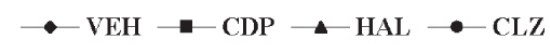

$4 \mathrm{~h}$

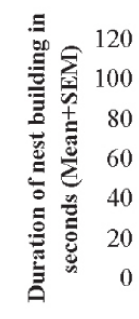

$1 \mathrm{~h}$

$2 \mathrm{~h}$

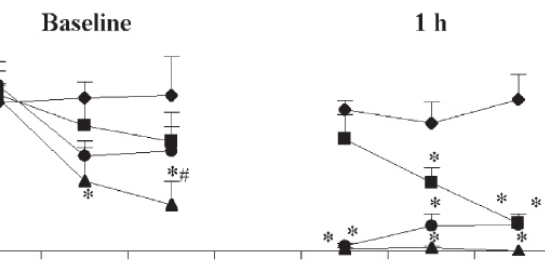

Day 8 Day 10 Day 12

D Pup nursing

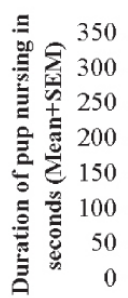

Baseline

$1 \mathrm{~h}$

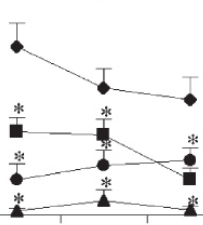

Day 8 Day 10 Day 12

Postpartum days

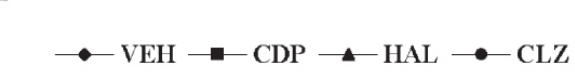
Data were expressed as mean+SEM. ${ }^{*} P<0.05$ indicates a significant difference between one drug group and the vehicle group; ${ }^{*} P<0.05$ indicates a significant difference between Day 8 postpartum and Day 12 postpartum.

$(p=0.014)$ on Day 8 postpartum only. In particular, CDP produced a disruptive effect on this behavior similar but somewhat weaker than that of HAL and CLZ (all ps < 0.05). Long-term potentiation of the drug effect was observed (Day 8 vs Day 12 Paired Samples $T$ test, $\mathrm{p}<0.05)$.

\subsubsection{Pup nursing}

Repeated measures ANOVA revealed a main effect of drug treat-
$=16.45, p=0.019$ for $4 \mathrm{~h}]$, a main effect of test time $\left[F_{(2,80)}=4.11, p=\right.$ 0.020 for $1 \mathrm{~h} ; F_{(2,80)}=9.78, p<0.001$ for $2 \mathrm{~h} ; F_{(2,80)}=4.78, p=0.011$ for $4 \mathrm{~h}$, but no significant interaction between the two factors at $1 \mathrm{~h}, 2$ $\mathrm{h}$ and $4 \mathrm{~h}$ testing points; there was a main effect of drug treatment $\left[F_{(3,40)}=3.21, p=0.033\right]$ but no significant effect of test time or significant interaction between the two factors at the baseline level. Post hoc tests showed that there were no consistent effects among the different drug conditions on nursing activity (Figure 3D). The same 


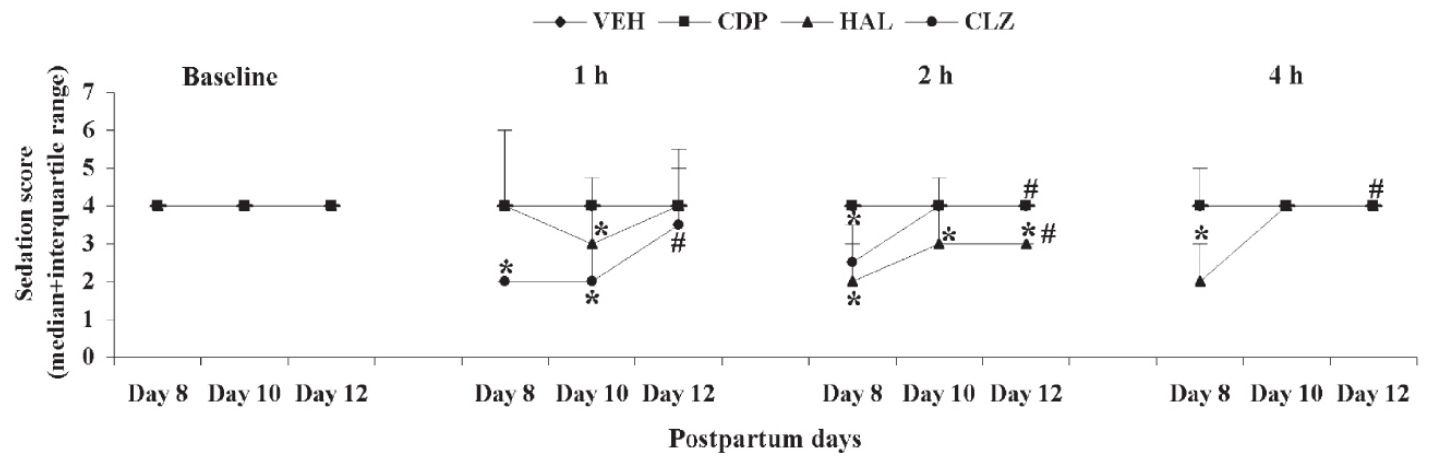

Fig. 4. Sedation scores in lactating rats treated with HAL, CLZ, CDP or Vehicle on Days 8,10 and 12 postpartum. Sedative effects were assessed at baseline, $1 \mathrm{~h}, 2 \mathrm{~h}$ and $4 \mathrm{~h}$ post-injection testing points. Data were expressed as median +interquartile range. ${ }^{*} P<0.05$ indicates a significant difference between one drug group and the vehicle group; ${ }^{\#} P<0.05$ indicates a significant difference between Day 8 postpartum and Day 12 postpartum.

For instance, HAL increased duration of pup nursing at the $1 \mathrm{~h}$ testing point on Day 10 and Day 12 postpartum, as well as $2 \mathrm{~h}$ on Day 12 postpartum, whereas it suppressed this behavior at $4 \mathrm{~h}$ on Day 8 postpartum. Also, CLZ enhanced this activity at baseline on Day 12 postpartum but reduced it at $2 \mathrm{~h}$ on Day 10 postpartum. Noticeably, CDP produced a prominent enhancing effect on the nursing behavior. Long-term potentiation of the drug effect was observed (Day 8 vs Day 12 Paired Samples T test, all $p$ s $<0.05$ ).

\subsubsection{Repeated antipsychotic treatment induced an attenuated sedation}

Figure 4 depicts the sedation scores of repeated treatment with HAL, CLZ, CDP, and vehicle over the four test sessions each day over the three test days. The sedative effect of HAL and CLZ tended to diminish over the testing period, whereas CDP at the present dose did not produce a noticeable sedation. Further analysis with MannWhitney $\mathrm{U}$ test showed that in comparison to the vehicle treatment, HAL induced a mild sedative effect at the $2 \mathrm{~h}$ post-injection testing point across the test days, whereas CLZ produced moderate sedation at $1 \mathrm{~h}$ and $2 \mathrm{~h}$ on Day 8, and at $2 \mathrm{~h}$ only on Day 10. Long-term alleviation of the drug sedative effect was observed (Day 8 vs Day 12 Wilcoxon's Two Related Samples Tests, all $p s<0.05)$. To examine to what extent that drug-induced sedation may contribute to the disruption on maternal behavior, we assessed the correlation between the disruptive effect of HAL and CLZ on the number of pups retrieved as a representative parameter of active maternl behaviors and the sedation scores of these drugs at the $2 \mathrm{~h}$ testing point from Day 8 to 12. We chose the $2 \mathrm{~h}$ point as the representation of the drug effect because the present and previous studies show that after a single injection of HAL and CLZ (Li et al., 2004a), the drug effects peak at $1-2 \mathrm{~h}$ post-injection. Spearman rank correlation analysis revealed that the disruptive effect of CLZ was strongly correlated with its sedative effect $(R s=0.502, p=0.002)$, whereas HAL-induced disruption was not correlated with its sedation $(R s=0.039, p=0.830)$. These results demonstrate that HAL-induced disruptive effect on active maternal behavior (number of pups retrieved) is mainly attributable to its effect of dopamine blockade but not sedation of the drug, but CLZ's sedative effect is at least in part responsible for CLZ-induced disruption on this active maternal behavior.

\section{Discussion}

In the present study, we showed that acute and chronic treatment with HAL and CLZ disrupted active maternal behaviors (e.g., pup retrieval, pup licking and nest building) in the postpartum female rats. More importantly, using the pup-separation technique, we found that separation of the pups from their mothers for $4 \mathrm{~h}$ before testing significantly enhanced pup licking activity and stimulated nursing behavior, an effect most likely attributable to the motivation-enhancing effect of pup-separation. In addition, with the repeated drug treatment, we showed that HAL progressively impaired active components of maternal responses (e.g., pup approach, pup retrieval and nest building), while HALinduced sedation was diminished across the test period. In contrast, the magnitude of both the disruptive and sedative effects of CLZ was reduced throughout the postpartum period, suggesting that the CLZ-induced disruption in pup retrieval may be partially attributed to its sedative side effect.

It is well documented that acutely administered antipsychotics disrupt active maternal behavior in rats, but generally have little effect, or even an enhancing effect on pup nursing (Giordano et al., 1990; Li et al., 2004a; Silva et al., 2001; Stern and Taylor, 1991). However the exact behavioral mechanisms underlying such an effect are not entirely clear. In the present study, we explored the possibility that antipsychotic-induced maternal behavior deficits may primarily reflect an inhibition on maternal motivation, an action that is likely mediated by antipsychotics' common antagonistic effect on dopamine $\mathrm{D}_{2}$ receptors (Kapur and Mamo, 2003). Toward this end, we employed a pup-separation technique because motherpup separation has been shown to enhance maternal motivation in the postpartum rats (Hansen, 1994; Hansen et al., 1993). This idea is based on the finding that separation of the lactating rats with 6-OHDA lesions in the ventral striatum from their pups for 3-6 $\mathrm{h}$ shortened their pup retrieval latency (Hansen, 1994). We reasoned that if pup-separation is able to antagonize the effect of dopamine blockade of the antipsychotics, it would suggest that the disruptive drug effect is mainly exerted on animals' motivation rather than on their motoric functions. To the best of our knowledge, there is no study that has directly compared the effect of pup-separation on the antipsychotic-induced maternal behavior deficits. We found that pup-separation significantly shortened clozapine-elongated approach latency, and increased pup licking in lactating dams, the most frequently observed pup-directed active behavior (Lonstein et al., 1999), while facilitating quiescent nursing activity (Stern, 1991; Stern and Taylor, 1991). These findings strongly suggest that pupseparation is capable of reversing some maternal behavior deficits to a certain extent, which in turn, indicates that antipsychotics may disrupt maternal behavior by inhibiting mothers' motivation to take care of the young, not simply impairing their motor functions. This point is also supported by the findings from Stern and Taylor (1991) and Li et al. (2004a). Stern and Taylor (1991) reported that HAL at $0.2 \mathrm{mg} / \mathrm{kg}$, a dose much higher than ours (HAL at $0.1 \mathrm{mg} /$ $\mathrm{kg}$ ), did not produce any disruption of pup retrieval, whereas Li et al. (2004a) found that it did. Our current study found that HAL even at $0.1 \mathrm{mg} / \mathrm{kg}$ produced a significant impairment on pup retrieval when rats were tested under the regular, no-pup-separation condition. One reason for this different result may lie in the fact that 
Stern and Taylor (1991) tested their rats under a 4-h mother-pup separation condition, whereas Li et al. (2004a) tested rats under the regular (no-pup-separation condition). The current finding showing that antipsychotic-treated rats responded to their pups differently under the separation and no-separation condition is consistent with this explanation.

Contrary to our results, a similar study using pup-separation skill showed that demanding pups (pups that remained separated from their mothers for $12 \mathrm{~h}$ before testing) significantly reversed all the deficits of active components of maternal behaviors (e.g., pup retrieval, mouthing, pup licking and nest building) in HAL-treated lactating females (Pereira and Ferreira, 2006). The different effects of pup-separation on HAL-induced maternal behavior impairments between the two studies may be due to the methodological differences. These differences include the HAL dose $(0.05 \mathrm{mg} / \mathrm{kg}$ vs 0.1 $\mathrm{mg} / \mathrm{kg}$ ), duration of separation (12 h vs $4 \mathrm{~h}$ ), testing duration (30 min vs $8 \mathrm{~min}$ ), etc. In addition, in that study, the mother rats were not separated from their litters until $15 \mathrm{~min}$ before testing and were tested with donor pups that were isolated for $12 \mathrm{~h}$, whereas in this present study, our subjects were separated from their own pups and tested with their own pups. Taken together the findings from both studies, it is interesting to speculate that a 12-h separation is more effective in stimulating maternal motivation and overcoming the impairments induced by a lower dose of HAL $(0.05 \mathrm{mg} / \mathrm{kg})$.

There are several possible factors associated with pup-separation that may increase maternal motivation and contribute to the different maternal performance observed under the pup-separation and no-separation condition. One possible factor is the increase of incentive value of separated pups. After an extended separation $(\sim 4 \mathrm{~h})$, pups are in acute need of active maternal care because they are hungry and they also need mothers to provide anogenital stimulation to help them urinate and defecate (Brouette-Lahlou et al., 1992). Also, separated pups may attract the mother rat's attention by emitting more audible and ultrasonic vocalizations (Brouette-Lahlou et al., 1992; Hofer, 1973; Iijima and Chaki, 2005; Polan and Hofer, 1999). Another possible factor is the change of physical condition of separated mothers. After a prolonged separation, milk engorgement of the mammary glands in dams may stimulate mother rats to approach to the sensory cues emitted by the pups and thereby increase their maternal performance. Previous work has shown two to three minutes separation is less effective in improving pup retrieval than a 4-6 h separation because shorter separation doses not allow sufficient distention of mammary glands (Hansen, 1994). Moreover, the degree of maternal responses to pups is found to be correlated with duration of separation from pups (Hansen, 1994). Given that dopamine plays an essential role in regulating maternal motivation through the mesolimbic dopamine system (Byrnes et al., 2002; Hansen et al., 1991b; McCullough et al., 1993; Miller and Lonstein, 2005; Numan et al., 2005; Robbins and Everitt, 1996), it is conceivable that separation-facilitated pup licking may be associated with an increase in mesolimbic dopamine release. This idea is consistent with the finding that the increase in dopamine level in the nucleus accumbens shell is significantly correlated with the magnitude and duration of the licking bout (Champagne et al., 2004). This hypothesis is further supported by earlier studies showing that dopamine receptor blockade in the nucleus accumbens disrupted pup licking (Keer and Stern, 1999; Stern and Lonstein, 2001), and reunion with separated pups significantly increases dopamine release in the ventral striatum of maternal rats (Hansen et al., 1993), and blockade of dopamine neurotransmission by haloperidol decreases exploratory behavior as measured by the reduced percentage of time spent in the open arms of the maze, whereas the presence of the pups in the open arms of the maze override such deficits provoked by haloperidol (Pereira et al., 2005).

In contrast to our expectation, pup-separation failed to reverse the antipsychotic-induced disruption of pup retrieval. We often observed that after reunion with the pups, the vehicle-treated rats rapidly approached and retrieved the pups into the nest site then started to lick the pups while adopting a hovering posture over the pups. However, for the antipsychotic-treated rats, after the pups were placed into the test cages, the dams often promptly commenced to lick them at the corner where the pups were placed, failed to retrieve them back to the nest site. This may explain why pup-separation had less of an effect on reversing the pup retrieval deficitinduced by antipsychotic treatment. We also failed to observe any effect of pup-separation on antipsychotic-induced disruption in nest building. During the 8-min pup retrieval session, we noted that after reunion with the pups, the mother rats spent most of their time on retrieving, licking and nursing pups, and spent less time on rebuilding the nest. The disrupted nest building behavior is not so easy to be restored relative to pup licking and pup retrieval is consistent with our previous observation that nest building activity is one component of rat maternal behavior most sensitive and vulnerable to pharmacological disturbance (Li et al., 2004a, 2005a; Silva et al.,2001).

To address whether and to what extent antipsychotic drug-induced sedation is associated with their disruption on active maternal behavior, we employed a repeated treatment regimen and recorded the sedation scores along with maternal performance. We also compared the effects of HAL and CLZ with CDP, an anxiolytic drug with sedative effect. Because sedation tends to dissipate with repeated drug treatment (Chesler and Salamone, 1996; File, 1984; Salamone et al., 1996), we reasoned that if it is a contributing factor, we would expect to see more severe disruption on maternal behavior at the early stage of testing than the later. Data from Days 8,10 and 12 postpartum indicate that with repeated drug administration, HAL and CLZ produced differential pattern of drug effect on active maternal behavior. HAL induced a sustained disruption on active component of maternal behavior throughout the drug treatment period in the background of a diminished seative effect. This observation discounts the sedation explanation for the disruptive effect of HAL. For CLZ, we found that both its disruptive effect on maternal behavior (e.g. pup retrieval) and its sedative effect were attenuated with the repeated drug administration and there was a significant correlation between the two, suggesting the CLZ-induced sedation may contribute to its disruptive effect on maternal behavior. It should be noted that animals used in the repeated treatment test were not experimentally or pharmacologically naïve at the start of the experiment. We could not rule out the potential carry-over effects produced by the previous drug administration or separation manipulation. There is a possibility that unmanipulated and drug-naïve animals would have had somewhat different behavioral profiles in Experiment 2. Future work using naïve animals and testing them for more days may help answer this question.

In the present study, we chose CDP as a pharmacological control to examine the specificity of antipsychotics' effect on maternal behavior. CDP, similar to atypical CLZ, also gives rise to sedation (File, 1984) but lacks the antipsychotic effect. We hypothesize that if the disruptive effect on maternal motivation is specific to antipsychotic drugs, we expect that CDP would not significantly disrupt active maternal behaviors but produce sedative effect to some extent. Surprisingly, we were unable to detect evident sedation induced by CDP at $5.0 \mathrm{mg} / \mathrm{kg}$, while others have shown it does (File, 1984). One possible explanation for the discrepancy may be due to methodological difference. In the previous work, the sedative effect of CDP was assessed by quantifying locomotor activity and exploration (File, 1984), while we measured sedation according to a sedation rating (Chesler and Salamone, 1996) in which locomotor activity and exploration were not quantitatively analyzed. We cannot completely exclude the possibility of reduced locomotor activity and exploration after CDP treatment, if any, in the present study as previously observed by File (1984). Another reason for the discrepancy may be the different subjects used in the two studies. Of note, lactating rats were used in the present study as opposed to male animals in the previous work. Reduced emotional and neuroendocrine stress responses such as reduced anxiety and fear have been described in lactation (Neumann et al., 2000; Windle et al., 1997). It is possible that the reduced anxious and fearful responses may make the lactating 
subjects less sensitive to the anxiolytic drugs (e.g., CDP). Earlier evidence in favor of this view came from the findings that the anti-anxiety effect of a serotonergic agonist, 8-hydroxy-2 (di-n-propylamino) tetralin (8-OH-DPAT) were completely absent in 7-day lactating rats (Fernández-Guasti et al., 1998; Picazo et al., 2000). Further study is needed to address this issue and determine whether CDP induces sedation in lactating rats and if it does, whether this sedative effect is less severe in lactating rats than male rats.

Finally, the relation between motor function and motivational processes is an additional point to consider in the present work. Because dopamine is closely associated with motor and motivational functions, and motor activity is an important feature of motivated behavior (Salamom ,ne, 1987, 1988),

it is somewhat difficult to draw a hard and fast line between motor and motivational systems in the brain. It has been argued that the motor and motivational processes overlap considerably and share some common mechanisms of regulation (Salamone, 1987, 1988, 1991, 1992; Salamone et al., 1989). In support of this view, our data reveal that some impairments of active maternal behavior are more easily reversible (e.g., pup licking), while others are not (e.g., nest building), suggesting that not all the motivated behaviors impaired by HAL and CLZ are equally restored with motivational manipulations (pup-separation).

In summary, the present study shows that the disruptive effect of antipsychotics on maternal behavior at least in part reflects its suppressive effect on maternal motivation as pup-separation significantly increases pup licking activity, one active component of maternal motivation. In addition, our repeated drug testing data also reveal that CLZ's sedative effect is also involved in its disruptive effect on maternal behavior. The fact that CDP did not impair maternal behavior except nest building suggests that antipsychoticinduced deficits may reflect a common effect of dopamine blockade (Li et al., 2004a). These findings suggest that behavioral techniques aimed at increasing maternal motivation may help alleviate the negative side effects of antipsychotic treatment on maternal behavior.

\section{Acknowledgements}

This work was supported by a grant from the National Institute of Mental Health (R03MH08822). We thank Wei He for his technical assistance with this research. We also thank two anonymous reviewers for their constructive comments.

\section{References}

Agid O, Kapur S, Arenovich T, Zipursky RB. Delayed-onset hypothesis of antipsychotic action: a hypothesis tested and rejected. Arch Gen Psychiatry 2003; 60: 1228-35.

Awad AG. Subjective response to neuroleptics in schizophrenia. Schizophr Bull 1993; 19: 609-18.

Awad AG, Hogan TP. Subjective response to neuroleptics and the quality of life: implications for treatment outcome. Acta Psychiatr Scand Suppl 1994; 380: 27-32.

Bosanac P, Buist A, Burrows G. Motherhood and schizophrenic illnesses: a review of the literature. Aust NZ J Psychiatry 2003; 37: 24-30.

Brouette-Lahlou I, Vernet-Maury E, Vigouroux M. Role of pups' ultrasonic calls in a particular maternal behavior in Wistar rat: pups' anogenital licking. Behav Brain Res 1992; 50: 147-54.

Byrnes EM, Rigero BA, Bridges RS. Dopamine antagonists during parturition disrupt maternal care and the retention of maternal behavior in rats. Pharmacol Biochem Behav 2002; 73: 869-75.

Champagne FA, Chretien P, Stevenson CW, Zhang TY, Gratton A, Meaney MJ. Variations in nucleus accumbens dopamine associated with individual differences in maternal behavior in the rat. J Neurosci 2004; 24: 4,11323.

Chesler EJ, Salamone JD. Effects of acute and repeated clozapine injections on cholinomimetic-induced vacuous jaw movements. Pharmacol Biochem Behav 1996; 54: 619-24.

Fernández-Guasti A, Picazo O, Ferreira A. Blockade of the anxiolytic action of 8-OH- DPAT in lactating rats. Pharmacol Biochem Behav 1998; 59: 45-50.
File SE. Behavioural pharmacology of benzodiazepines. Prog Neuropsychopharmacol Biol Psychiatry 1984; 8: 19-31.

Fleischhacker WW, Meise U, Gunther V, Kurz M. Compliance with antipsychotic drug treatment: influence of side effects. Acta Psychiatr Scand Suppl 1994; 382: 11-5.

Giordano AL, Johnson AE, Rosenblatt JS. Haloperidol-induced disruption of retrieval behavior and reversal with apomorphine in lactating rats. Physiol Behav 1990; 48: 211-4.

Hansen S. Maternal behavior of female rats with 6-OHDA lesions in the ventral striatum: characterization of the pup retrieval deficit. Physiol Behav 1994; 55: 615-20.

Hansen S, Harthon C, Wallin E, Löfberg L, Svensson K. Mesotelencephalic dopamine system and reproductive behavior in the female rat: effects of ventral tegmental 6-hydroxydopamine lesions on maternal and sexual responsiveness. Behav Neurosci 1991a; 105: 588-98.

Hansen S, Harthon C, Wallin E, Löfberg L, Svensson K. The effects of 6-OHDAinduced dopamine depletions in the ventral or dorsal striatum on maternal and sexual behavior in the female rat. Pharmacol Biochem Behav 1991b; 39: 71-7.

Hansen S, Bergvall AH, Nyiredi S. Interaction with pups enhances dopamine release in the ventral striatum of maternal rats: a microdialysis study. Pharmacol Biochem Behav 1993; 45: 673-6.

Hofer MA. Maternal separation affects infant rats' behavior. Behav Biol 1973; 9: 629-33.

Iijima M, ChakiS.Separation-induced ultrasonic vocalization in rat pups: further pharmacological characterization. Pharmacol Biochem Behav 2005; 82: 652-7.

Ikemoto S, Panksepp J. The role of nucleus accumbens dopamine in motivated behavior: a unifying interpretation with special reference to reward-seeking. Brain Res Brain Res Rev 1999; 31: 6-41.

Joordens RJ, Hijzen TH, Olivier B. The anxiolytic effect on the fear-potentiated startle is not due to a non-specific disruption. Life Sci 1998; 63 : $2,227-32$

Kapur S, Mamo D. Half a century of antipsychotics and still a central role for dopamine $\mathrm{D}_{2}$ receptors. Prog Neuropsychopharmacol Biol Psychiatry 2003; 27: $1,081-90$

Kapur S, VanderSpek SC, Brownlee BA, Nobrega J. Antipsychotic dosing in preclinical models is often unrepresentative of the clinical condition: a suggested solution based on in vivo occupancy. J Pharmacol Exp Ther 2003; 305: 1-7.

Keer SE, Stern JM. Dopamine receptor blockade in the nucleus accumbens inhibits maternal retrieval and licking, but enhances nursing behavior in lactating rats. Physiol Behav 1999; 67: 659-69.

Klint T. Effects of 8-OH-DPAT and buspirone in a passive avoidance test and in the elevated plus-maze test in rats. Behav Pharmacol 1991; 2: 481-9.

Li M, Davidson P, Budin R, Kapur S, Fleming AS. Effects of typical and atypical antipsychotic drugs on maternal behavior in postpartum female rats. Schizophr Res 2004a; 70: 69-80.

Li M, Parkes J, Fletcher PJ, Kapur S. Evaluation of the motor initiation hypothesis of APD-induced conditioned avoidance decreases. Pharmacol Biochem Behav 2004b; 78: 811-9.

Li M, Budin R, Fleming AS, Kapur S. Effects of novel antipsychotics, amisulpiride and aripiprazole, on maternal behavior in rats. Psychopharmacology (Berl) 2005a; 181: 600-10.

Li M, Budin R, Fleming AS, Kapur S. Effects of chronic typical and atypical antipsychotic drug treatment on maternal behavior in rats. Schizophr Res 2005b; 75: 325-36.

Li M, Fletcher PJ, Kapur S. Time course of the antipsychotic effect and the underlying behavioral mechanisms. Neuropsychopharmacology 2007; 32: 263-72.

Lonstein JS, Fleming AS. Parental behaviors in rats and mice. Curr Protoc Neurosci 2002; 8.15: 1-26

Lonstein JS, Wagner CK, DeVries GJ. Comparison of the "nursing" and other parental behaviors of nulliparous and lactating female rats. Horm Behav 1999; 36: 242-51.

McCullough LD, Cousins MS, Salamone JD. The role of nucleus accumbens dopamine in responding on a continuous reinforcement operant schedule: a neurochemical and behavioral study. Pharmacol Biochem Behav 1993 46: 581-6.

McNeil TF, Näslund B, Persson-Blennow I, Kaij L. Offspring of women with nonorganic psychosis: mother-infant interaction at three-and-a-half and six months of age. Acta Psychiatr Scand 1985; 71: 551-8.

Miller SM, Lonstein JS. Dopamine d1 and d2 receptor antagonism in the preopticarea produces different effects on maternal behavior in lactating rats. Behav Neurosci 2005; 119: 1,072-83.

Näslund B, Persson-Blennow I, McNeil TF, Kaij L. Offspring of women with nonorganic psychosis: mother-infant interaction at three and six weeks of age. Acta Psychiatr Scand 1985; 71: 441-50. 
Neumann ID, Torner L, Wigger A. Brain oxytocin: differential inhibition of neuroendocrine stress responses and anxiety-related behaviour in virgin, pregnant and lactating rats. Neuroscience 2000; 95: 567-75.

Numan M, Numan MJ, Pliakou N, Stolzenberg DS, Mullins OJ, Murphy JM, et al. The effects of $\mathrm{D}_{1}$ or $\mathrm{D}_{2}$ dopamine receptor antagonism in the medial preopticarea, ventral pallidum, or nucleus accumbens on the maternal retrieval response and other aspects of maternal behavior in rats. Behav Neurosci 2005; 119: 1,588-604.

Pereira M, Ferreira A. Demanding pups improve maternal behavioral impairments in sensitized and haloperidol-treated lactating female rats. Behav Brain Res 2006; 175: 139-48.

Pereira M, Uriarte N, Agrati D, Zuluaga MJ, Ferreira A. Motivational aspects of maternal anxiolysis in lactating rats. Psychopharmacology (Berl) 2005; 180: 241-8.

Persson-Blennow I, Näslund B, McNeil TF, Kaij L, Malmquist-Larsson A. Offspring of women with nonorganic psychosis: mother-infant interaction at three days of age. Acta Psychiatr Scand 1984; 70: 149-59.

Persson-Blennow I, Näslund B, McNeil TF, Kaij L. Offspring of women with nonorganic psychosis: mother-infant interaction at one year of age. Acta Psychiatr Scand 1986; 73: 207-13.

Picazo O, Rosenblatt JS, Fernández-Guasti A. The differential effect of the anxiolytic agent 8-OH-DPAT during lactation is independent of pup withdrawal and maternal behavior. Psychoneuroendocrinology 2000; 25: 693-706.

Polan HJ, Hofer MA. Maternally directed orienting behaviors of newborn rats. Dev Psychobiol 1999; 34: 269-79.

Riordan D, Appleby L, Faragher B. Mother-infant interaction in post-partum women with schizophrenia and affective disorders. Psychol Med 1999; 29: 991-5.

Robbins TW, Everitt BJ. Neurobehavioural mechanisms of reward and motivation. Curr Opin Neurobiol 1996; 6: 228-36.

Salamone JD. The actions of neuroleptic drugs on appetitive instrumental behaviors. In: Iversen LL, Iversen SD, Snyder SH, editors. Handbook of Psychopharmacology. NewYork: Plenum Press; 1987. p. 575-608.

Salamone JD. Dopaminergic involvement in activational aspects of motivation: effects of haloperidol on schedule-induced activity, feeding and foraging in rats. Psychobiology 1988; 16: 196-206.

Salamone JD. Behavioral pharmacology of dopamine systems: a new synthesis. In: Willner P, Scheel-Kruger J, editors. The Mesolimbic Dopamine System: From Motivation to Action. Cambridge: Cambridge University Press; 1991. p. 599-613.

Salamone JD. Complex motor and sensorimotor functions of striatal and accumbens dopamine: involvement in instrumental behavior processes.
Psychopharmacology (Berl) 1992; 107: 160-74.

Salamone JD, Correa M. Motivational views of reinforcement: implications for understanding the behavioral functions of nucleus accumbens dopamine. Behav Brain Res 2002; 137: 3-25.

Salamone JD, Keller RW, Zigmond MJ, Stricker EM. Behavioral activation in rats increases striatal dopamine metabolism measured by dialysis perfusion. Brain Res 1989; 487: 215-24.

Salamone JD, Cousins MS, Maio C, Champion M, Turski T, Kovach J. Different behavioral effects of haloperidol, clozapine and thioridazine in a concurrent lever pressing and feeding procedure. Psychopharmacology (Berl) 1996; 125: 105-12.

Sanger DJ. The effects of clozapine on shuttle-box avoidance responding in rats: comparisons with haloperidol and chlordiazepoxide. Pharmacol Biochem Behav 1985; 23: 231-6.

Seeman MV. Schizophrenia and motherhood. In: Göpfert M, Webster J, Seeman MV, editors. Parental Psychiatric Disorder: Distressed Parents and Their Families. Cambridge: Cambridge University Press; 2004. p.161-71.

Silva MR, Bernardi MM, Felicio LF. Effects of dopamine receptor antagonists on ongoing maternal behavior in rats. Pharmacol Biochem Behav 2001; 68: 461-8.

Snellen M, Mack K, Trauer T. Schizophrenia, mental state, and mother-infant interaction: examining the relationship. Aust NZ J Psychiatry 1999;33:902-11.

Stern JM. Nursing posture is elicited rapidly in maternally naive, haloperidoltreated female and male rats in response to ventral trunk stimulation from active pups. Horm Behav 1991; 25: 504-17.

Stern JM, Keer SE. Maternal motivation of lactating rats is disrupted by low dosages of haloperidol. Behav Brain Res 1999; 99: 231-9.

Stern JM, Lonstein JS. Neural mediation of nursing and related maternal behaviors. Prog Brain Res 2001; 133: 263-78 [Review].

Stern JM, Taylor LA. Haloperidol inhibits maternal retrieval and licking, but facilitates nursing behavior and milk ejection in lactating rats. J Neuroendocrinol 1991; 3: 591-6.

Wan MW, Salmon MP, Riordan DM, Appleby L, Webb R, Abel KM. What predicts poor mother-infant interaction in schizophrenia? Psychol Med 2007; 37: 537-46.

Wan MW, Penketh V, Salmon MP, Abel KM. Content and style of speech from mothers with schizophrenia towards their infants. Psychiatry Res 2008; 159: 109-14.

Windle RI, Wood S, Shanks N, Perks P, Conde GL, daCosta AP, et al. Endocrine and behavioural responses to noise stress: comparison of virgin and lactating female rats during non-disrupted maternal activity. J Neuroendocrinol 1997; 9: 407-14 